\title{
The Psychology of Stroke in Young Adults: The Roles of Service Provision and Return to Work
}

\author{
Reg Morris \\ School of Psychology, Cardiff University, and Cardiff and Vale University Local Health Board, Archway House, 77 TY Glas Avenue, \\ Llanishen, Cardiff CF14 5DX, UK \\ Correspondence should be addressed to Reg Morris, reg.morris@wales.nhs.uk
}

Received 4 September 2010; Revised 23 December 2010; Accepted 9 January 2011

Academic Editor: Halvor Naess

Copyright ( 2011 Reg Morris. This is an open access article distributed under the Creative Commons Attribution License, which permits unrestricted use, distribution, and reproduction in any medium, provided the original work is properly cited.

Literature about the psychological consequences of stroke in those under 65 is reviewed focussing on services and work. Despite similarities, young and old survivors have different experiences and needs. These are attributable to the effects of stroke on age-normative roles and activities, self-image, and the young person's stage in the life-cycle, especially family and work. "Hidden" cognitive impairments, a disrupted sense of self, and the incongruity of suffering an "older person's" disease are salient. Young survivors benefit from services, but experience lack of congruence between their needs and service philosophy, methods, and aims, and consequently have unmet needs. Employment is psychologically salient, and the evidence about return rates, factors that affect return, and the adequacy of employment-related service provision is reviewed. Specific and general recommendations are made for increasing congruence between young survivors' needs and service provision and also for facilitating their return to work.

\section{Definitions and Scope}

In this paper a "young" stroke survivor will be considered to be someone aged 18 to 65 years. The lower boundary ties in with the current dividing line between childhood and adulthood, and the upper boundary with the division between working age and old age health services in many countries. This paper is based upon literature searches of several data bases (ASSIA, AMED, British Nursing Index, Cochrane database of systematic reviews, MEDLINE, PsychInfo, SCOPUS, Zetoc, Google Scholar). Reference lists of relevant articles were scanned, and papers that cited articles were also examined to supplement these searches. Reviews and original articles that included material of psychological relevance were selected for further scrutiny and possible inclusion. The focus of the paper is upon factors that affect the psychological adjustment of stroke survivors, particularly service provision and employment.

\section{Introduction}

The risk of stroke increases with age, and the relationship with age is universally found across nations [1]. The incidence of stroke in younger people is low, but the population demographics of age mean that a significant proportion of new strokes occur in the under 65s. This proportion has been estimated as $21 \%$ in the UK [2]. As an example, a country of the size of England, with a population of about 50 million, and about 29 million under 45, would expect around 5,800 new strokes in people under 45 each year. Since people who have a stroke when young are likely to live longer than their elderly counterparts, the prevalence rate for younger strokes is about $25 \%[2,3]$. Younger people have proportionately more haemorrhagic strokes $[4,5]$, and ethnic differences in the risk of stroke are accentuated in younger age groups [6].

\section{Stroke and Psychological Adjustment in the Young}

The psychological effects of stroke and the evidence for their occurrence are summarised in Table 1.

Quality of life after stroke for all age groups was impaired in comparison with comparable healthy adults $[7,8]$, and studies comparing the quality of life of younger and older 
TABLE 1: Psychological adjustment in young stroke survivors.

\begin{tabular}{l}
\hline Attribute \\
\hline Reduced quality of life. Associated with \\
dependence, depression, being single, fatigue, and
\end{tabular}

stroke survivors have produced inconsistent findings [7]. Reduced quality of life in young survivors was associated with dependence, depression, being single, fatigue, and being unemployed [9], and different factors, including type of stroke, visual field impairment, and seizures may be associated with quality of life only in older survivors [8].

Young and old stroke survivors have much in common, but young survivors have particular needs, both practical and psychological. A study of stroke survivors under 50 years of age [4] found that family conflict and loss of home, employment, and spouse were common practical problems. In the case of employment loss the rate was
80\%-90\%. Staff reported that about half of survivors had psychological disorders, especially depression or anxiety. The anxiety mainly focussed on work, but also related to recovery and childcare. Around a quarter to a third exhibited denial, anger, frustration, or hostility. Problems with employment, finances, and social participation, as well as marital difficulties, including sexual problems, were also reported in a UK questionnaire survey [2]. These results were echoed in the conclusions of a review of 78 studies of young stroke survivors [10], and this review also noted that problems were frequently attributed to the stroke. However, the percentage of survivors reporting problems varied considerably across studies and problems, typically from $5 \%$ to around $70 \%$. Body image was found to decline following stroke in a mixed gender group under 40 years old [16]. This was most marked in those with left hemisphere strokes and was associated with a reduction in physical and global measures of self-esteem. Frustration was a core theme found in a qualitative study of survivors under 55 years old, for up to two years after a first stroke [11]. The frustration was related to a sense of psychological paralysis stemming from omnipresent fatigue that affected everyday activities and gender roles, particularly the roles of mother, father, provider, and housekeeper. It was also fuelled by the sense of being "outside and invisible" which revolved around lack of information, lack of consideration of young survivors' needs, a shortage of age-appropriate activities, and their awareness of their "invisible" cognitive impairments. This study also reported positive outcomes of stroke, including new roles and perspectives that improved adjustment. The small sample limited the generality of the results, but there was corroboration from large-scale followup studies [12, 13] as well as independent research [14]. More than half of young survivors perceived themselves to have enduring physical and cognitive disabilities and were dissatisfied with life after stroke [13] and many experienced problems caused by paralysis due to fatigue and the "invisibility" of disabilities which predisposed colleagues, family, or friends to discount, ignore, or deny the "authenticity" of the survivor's limitations [14]. Objective evidence for cognitive difficulties in younger stroke survivors (under 45 at time of stroke) was provided by a comparison of neuropsychological test performance of young stroke survivors and matched controls, and there was also a marked contrast between the good recovery of function and mobility in the stroke survivors and the poor recovery of cognition [22]. A study of people with mild stroke [17] further supported these findings and concluded that life satisfaction in this group was affected by subtle impairments including impaired executive function, attention, and other neurological deficits: the rapid recovery of overt, noticeable physical functions created a false impression of generalised recovery that was not paralleled in the less obvious cognitive domain. Finally, a synthesis of four qualitative studies proposed that the experience of young stroke survivors may be encompassed by three overarching domains: "disorientation" due to the sudden effects of stroke, "disrupted sense of self" due to changed self-perception and "loss of control" which may in turn lead to changed priorities, and finally "roles and relationships" 
which change due to dependency and impaired functioning [15].

Young survivors face the added psychological task of reconciling the perceived incongruity of suffering an older person's disease at an early age [14] and being treated in services in which older people predominate. This challenges self-identity, or social identity; the way that a person views and experiences themselves and their relationships with significant others and social groups [23]. Identity is a general, central aspect of psychological adjustment, and is important in the efforts of brain injured people to make sense of themselves and their circumstances [18]. Continuity in self-identity has been demonstrated to impact on the psychological well-being of stroke survivors $[19,20]$.

Sense of self-efficacy, or competence, emerged as an important aspect of identity in a study of young neurological and stroke patients [21]. The patients understood their own and others' roles in relation to rehabilitation in several ways; independence and self-reliance were important, as were determination, pushing limits, and recognition of progress. Professionals and rehabilitation processes were perceived as vital factors influencing self-efficacy, as were vicarious experiences through contact with other patients. However, a singular feature was the way in which a higherorder understanding of the purpose of rehabilitation influenced adjustment. Survivors adopted contrasting views of rehabilitation, as either a process that led to "restitution" of former life, or a process that enabled and supported adaptation, adjustment and change to meet the demands of new circumstances. Taking the perspective of rehabilitation as supporting adaptation was considered to improve adaptation, reduce disappointment, and was more congruent with the aims of professionals.

\section{Young Stroke Survivors' Experiences of Services}

Young stroke survivors' access to components of stroke care such as specialist stroke units and time with professional staff differed sharply between countries and world regions, as did their fatality rates and functional outcomes [24]. The national stroke strategies and guidelines of wealthier nations generally recognise the special and different needs of younger stroke survivors. For example, the UK National Clinical Guidelines for Stroke [3] state that "Some younger adults feel that general stroke services, of which the majority of users are older adults, do not meet their needs" (page 32) and recommend that the particular needs of this group are considered, especially vocational rehabilitation and child care, and that services are "provided in an environment suited to their specific social needs" (page 32). However, national stroke strategies around the world do not recommend separate care services for young stroke survivors (e.g., the European Stroke Strategy [25]; the Australian Stroke Strategy [26, 27]; the Canadian Stoke Strategy [28]). Consequently, young stroke survivors receive treatment within stroke care services in which the majority of patients are over 65.
As for stroke survivors in general [29], the quality of life, physical function, and cognition of young survivors all improved when specialist stroke care was provided [30]. It has been suggested that the outcomes of younger and older stroke survivors may be comparable and that the needs of the two groups are substantially similar [31]. This received support from the finding that, although greater age did predict lower absolute functional scores at discharge, the effect of age alone on improvement in functioning was small and accounted for less than $2 \%$ of variation [32]. Moreover, there is evidence demonstrating that age interacts with other factors to determine outcome; survivors under 75 years old achieved better outcomes than older survivors when treated on specialist stroke units, but not when treated on general wards [33]. A review of 13 studies examining the influence of age on outcome noted that results were inconsistent. One large-scale survey demonstrated that differential treatment for younger and older stroke patients may underpin outcome differences; the greater functional improvement and chances of returning home of young patients may have been a consequence of them receiving, on average, substantially longer hospital treatment than older patients [34].

Few studies have compared the services experienced by younger and older stroke survivors. A study in a neurovascular clinic for people with TIAs or mild strokes compared patients over and under 75 years and found no differences in appointment times, preventative treatments offered, or in rates of receiving CT scans [35]. However younger people were more often given life-style advice about diet and weight, they were CT scanned sooner, and more of them received MRI scans and carotid Doppler investigations (but older people received carotid endarterectomy more rapidly). Two studies that compared age groups (18-45 and 46-65) found that younger patients had more unmet needs in relation to holidays, intellectual fulfilment, and family support, despite having the same number of unmet needs overall $[2,36]$. Unfortunately these two studies drew participants from several different services in an unsystematic way, so service factors could account for the age differences.

A questionnaire survey of young survivors at a median of three years after stroke [2] found that GP services were widely used by their informants $(77 \%$ had consulted within the 12 months before the survey), $24 \%$ had utilised third sector stroke organisations (Different Strokes and the Stroke Association), and $15 \%$ to $38 \%$ received specialist rehabilitation input, with physiotherapy being the most frequent. However, the median number of unmet needs was two, with the most common being personalised information about their stroke and assistance with finances, noncare activities, intellectual fulfilment, adaptations, vehicles and social contacts. Those with impaired mobility and those who did not return to work reported more unmet needs. Employment and sexual difficulties were additional needs, and sexual difficulty rates were much higher than the $40 \%$ for women and $30 \%$ for men found in the general population [37]. A survey conducted in young stroke groups [36] found results concordant with those above, except that there was a higher rate of unmet needs (median 5). The most often reported service shortfalls were once again personalised 
information about the person's stroke, help with finances, assistance with social activities, and assistance in achieving intellectual fulfilment. An in-depth study of response to service provision in 50 survivors (18-49 years old), their relatives, and care staff, covering the period from stroke onset to returning to the community and "moving on," found some additional needs. Young survivors wanted services that focussed on the needs of younger people and considered their family responsibilities, need for employment rehabilitation, difficulties in claiming welfare benefits, child-care problems, and issues regarding employment for their spouse carers. Two further in-depth studies $[11,38]$ using interviews or case notes suggested that rehabilitation staff were not attuned to the concerns and needs of young stroke survivors and did not formulate their problems effectively or set appropriate goals; while the survivors were preoccupied with loss of control, fatigue, and fear of another stroke, the staff focussed upon functional deficits and training. There was a perceived lack of age-appropriate activities and environments and lack of attention to "invisible" cognitive impairments. Qualitative analyses of separate focus groups of survivors and staff [39] also identified differences between staff and survivors' perceptions of needs. This study included older as well as younger survivors, suggesting that this disparity is not unique to young survivors and many of the service deficits identified in young survivors [40] were shared by older survivors including service variation, poor communication, lack of personalised information, lack of understanding of effects of stroke on patient and family, low involvement in decision-making, gaps in postdischarge support, and gaps in community support.

While the negative service experiences of younger stroke survivors may be partly attributable to failure to identify and respond to their particular needs, the dissatisfaction and distress arising from the experiences of young stroke survivors in health services may not be entirely a function of the services themselves, and may be partly psychological in origin, stemming from the threats to a young person's selfconcept and identity $[14,15,18-20]$ posed by being treated in services where older people predominate.

\subsection{Implications for Services Supporting Young Stroke Sur-} vivors. There are currently no evidence-based, interventions specifically designed for young stroke survivors. However, a few general recommendations can be made on the basis of the evidence reviewed above. Caring for young children, relationships with spouse, sexuality, invisible cognitive disabilities, fatigue that affects engagement in ageappropriate activities, loss of employment, reduced intellectual fulfilment, and financial problems seem to be especially salient practical issues. Addressing these adequately not only requires skilled therapists but also networking with nonhealthcare agencies such as employers, social services, job-centres, marital counselling services, and communitybased education or leisure facilities. Second, young stroke survivors experience major threats to their self-identity through being isolated from their peers, being unable to meet normal expectations for the leisure and employment activities of young people, having a reduced sense of selfefficacy due to their disabilities and restrictions, experiencing a sharp discontinuity between their prestroke self and their current self, and finally by having what is perceived as an “old person's disease." Young survivors should be afforded opportunities for psychologically oriented counselling and support when well-being is affected by change in identity and a sense of discontinuity. Young stroke survivors require help to understand the wider goal of rehabilitation as a process of adjustment and adaptation to changed capabilities and circumstances rather than simply the "restitution" of former patterns of activity. Peer support is widely employed to assist the adjustment of stroke survivors by voluntary stroke groups, but has been only sparsely researched and its benefits for stoke survivors are not fully established. However, it was included in the National Stroke Strategy for England [41], and there is some evidence for its effectiveness in supporting the psychological well-being of stroke carers (see Section 5.2.)

\section{Work after Stroke}

The total economic cost of stroke to the UK economy has

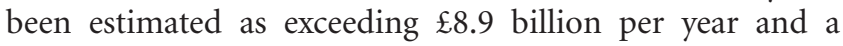
substantial proportion of the total is attributable to the cost of loss of employment and benefits payments $(\mathfrak{£} 2.2$ billion) [42]. In addition to its economic importance, the benefit of work for individual health and well-being has been recognised. It is an important source of income essential for material well-being and participation in society, and it also meets psychosocial needs, helps develop and maintain individual identity, social roles, and social status, and is associated with physical and mental health and longevity. Conversely, worklessness is associated with greater mortality, poorer mental and physical health, and greater use of healthcare resources [43].

5.1. Work and Young Stroke Survivors. Work is valued and a salient issue for stroke survivors, even for those not working prior to their stroke $[55,64]$, and not having work after stroke is often perceived as a major problem [64]. Many young stroke survivors were working at the time of the stroke and, perhaps just as important, so were their partners. For some the stroke may present an opportunity to change lifestyle, take early or medical retirement, or to explore eligibility for age-related benefits. For others, particularly those with dependent children, these routes may not be an option. Reported rates of return to work after stroke vary widely, due to contextual and methodological differences between studies. A review of 16 studies conducted in 12 developed countries [65] identified rates ranging from 14\% to $73 \%$ with a median value of around $50 \%$. Most of those returning to work did so quickly, usually in 3-6 months, but there were reports of a second peak at 12-18 months, perhaps when the consequences of long-term unemployment began to impact. Daniel et al. [10] found the mean percentage returning to work to be $44 \%$ (range 0 to $100 \%$ ) in a review 
TABLE 2: Facilitators and barriers for return to work.

\begin{tabular}{|c|c|c|c|}
\hline Dimension & & & Evidence \\
\hline Better functioning versus impaired functioning. & & & {$[44-51]$} \\
\hline Holding a full-time job versus a part-time job & & & {$[52]$} \\
\hline Having an office-based rather than a manual job & & & {$[45,46,49,50]$} \\
\hline $\begin{array}{l}\text { Being male, white, or of high socioeconomic status versus } \\
\text { being female, black, or of low socioeconomic status }\end{array}$ & & & {$[51,53,54]$} \\
\hline Preserved cognitive ability versus cognitive impairments & & & {$[45,46,48-50]$} \\
\hline $\begin{array}{l}\text { Sympathetic flexible employers versus inflexible } \\
\text { employer }\end{array}$ & & & [55-58] \\
\hline Specific Facilitators & Evidence & Specific Barriers & Evidence \\
\hline Positive personal attributes (patience, determination) & {$[56]$} & $\begin{array}{l}\text { Stroke symptoms that impair specific work } \\
\text { competences }\end{array}$ & [57-59] \\
\hline Support from families and social networks & {$[55,56]$} & Fatigue & {$[11,56]$} \\
\hline Support from health care professionals & {$[56]$} & Having a psychological disorders & {$[52,60]$} \\
\hline Disability legislation and statutory sick leave & {$[61]$} & Perceived stressfulness of work & {$[55,59]$} \\
\hline Employment tasks that can be flexibly configured. & {$[55,56]$} & Benefits systems that encourage nonreturn to work & {$[57,58,61]$} \\
\hline Previous positive experience of work & {$[55]$} & Lack of understanding of stroke by employers & {$[61]$} \\
\hline Valuing work and its intrinsic rewards & {$[53,61-63]$} & Lack of information about returning to work & {$[61]$} \\
\hline
\end{tabular}

that included 70 studies, but studies of return at 6-12 months after stroke found the rate to be slightly over $50 \%$.

Several studies have attempted to identify factors that influence return to work after stroke. Successful return to work has been shown to be associated with individual factors such as absence of dysphasia [44], higher functioning on discharge [44-51], shorter rehabilitation stay [44, 48], lack of apraxia $[45,46]$, freedom from psychological disorders [52, $60]$, preserved cognitive abilities [48-50], and low alcohol intake prior to stroke [44]. Employment factors were also important determinants of return to work, and blue-collar (manual) workers returned sooner $[45,46]$, but white-collar (office) workers were more likely to return to work in the long term $[45,46,49,50]$. Being in full-time employment prior to stroke [52] and having a positive attitude to work [53] were also associated with successful return, as were higher socioeconomic status [53], not being black [51], being male $[51,54]$, and receiving support from others [53]. Stroke location was not predictive of resumption of work in one study that examined this relationship [46]. Return to work was found to be associated with higher quality of life [47], well-being, and life-satisfaction [49]. A questionnaire survey $[57,58]$ of stroke survivors found that $75 \%$ of respondents said they would like to return to work, but $36 \%$ felt that they could not, and $43 \%$ had not been able to return to work, although $31 \%$ had worked since their stroke. Reasons given for not returning to work included: forced to retire by employer; cannot meet expectations; cannot drive/use public transport; afraid of losing benefits; not fit enough to work; can no longer do previous job.

Several studies have used in-depth qualitative methods to explore experiences of work in stroke survivors. Interviews with 43 survivors under 60 found that returning to work was a salient issue for the participants and a benchmark for successful recovery. The participants valued work and its benefits, including those not working before their stroke [55]. Another study of right hemisphere stroke survivors and their carers found that the stroke precipitated employment changes for all, and these employment changes had a substantial psychosocial impact on both the stroke survivor and the carer [56]. Lock et al. [61] studied stroke survivors and carers and reported four principal themes of relevance to work: rehabilitation process, employer agency, socialstructural factors, and personal factors. Rehabilitation process was seen as being focussed on minimal physical recovery, time-limited and not sufficiently oriented to employment. Survivors responded to the shortfall in rehabilitation by taking control and pursuing their own goals, but also acknowledged the importance of family support and support from co-workers. The benefits system militated against return to work, and, in addition, information about support and opportunities for returning to work was limited. The UK Disability Discrimination Act [66] and sick leave arrangements were considered to facilitate return, but employers' inflexibility, ignorance about stroke, and negative attitudes were barriers. This latter finding is echoed by studies demonstrating that flexible, sympathetic work environments and practices, and supportive social networks facilitated return to work $[55,56]$, as did instrumental and emotional support from healthcare professionals [56]. As in other studies $[11,56]$, fatigue was seen as the major personal factor in returning to work, and perceived cognitive impairments were also implicated. One study [55] reported that return to work hinged upon the relative impact of barriers and facilitators; stress, and its possible consequences for health, was one such factor, as were past experiences with working or not working and severe residual disabilities which could make working impossible. Lock et al. [61] also identified 
TABle 3: Promoting return to work.

\begin{tabular}{lll}
\hline Consideration/Factor & Evidence & Implications \\
\hline $\begin{array}{l}\text { A very high proportion of young } \\
\text { survivors wish to return to work. }\end{array}$ & & \\
$\begin{array}{l}\text { Employment is a central life role, } \\
\text { bringing intrinsic rewards. }\end{array}$ & {$[49,55,62,64]$} & (i) Consider employment in rehabilitation goal planning for all \\
$\begin{array}{l}\text { Return to work is associated with } \\
\text { better life-satisfaction and }\end{array}$ & & \\
quality of life. & & \\
\hline
\end{tabular}

A significant proportion of those working before stroke will not return to work. Many of these will want to return.

(i) Psychological therapy should consider this as a major and sudden "loss".

$[2,4,52,56,57,64] \quad$ (ii) Such survivors and their carers may require help with adjustment to new circumstances.

(iii) Encourage survivors to explore creative approaches to developing alternative activities.

(i) Provide vocational advice on suitable types of work.

(ii) Encourage flexibility and exploration of options in survivors.

Many survivors return to different types of work, including voluntary work.

(iii) Develop awareness of the Disability Discrimination Act and flexible provisions for disabled employees.

(iv) Develop connections with potential employers including voluntary organizations.

A positive attitude to return to work is important.

$[53,55,63]$

(i) Individual and group therapeutic interventions to promote the benefits of work and influence attitudes may be beneficial.

Social, demographic and economic factors are important.

(i) Wide variation in return rates between different countries.

(ii) Socioeconomic status predicts return to work

(iii) Gender, ethnicity, and age are associated with return

Employers' attitude and support are important determinant of return

(i) Advocacy should be available for those who wish to return to work.

(ii) Stroke service should network with agencies that find employment, retrain, or support employment.

(iii) Network with employers and/or human resources departments to build support for return to work.

(i) Return to original employment may not be realistic in all cases.

(ii) Professionals should provide realistic feedback, considering the

Residual disabilities, physical ability and especially weakness are related to return.

$[44-46,48,53,54,56,59,64]$ survivors readiness to accept it. Premature pessimistic prognosis should be avoided.

(iii) Flexible, phased return may be helpful.

(iv) Long-term support may be required.

(i) Recognise fatigue as a common barrier to returning to work.

Fatigue is an important factor in $\quad[11,56,61,64]$ return.

(ii) Consider fatigue management as part of psychological therapy.

(iii) Plan return to work allowing for effects of fatigue. A phased return may be helpful.

(i) Cognitive assessment for all intending to return to work.

"Hidden" cognitive deficits are a concern for survivors.
$[11,14,48-50,53,56,61]$ (ii) Consider cognitive rehabilitation.

(iii) Consider "information prosthesis" and compensatory measures (diaries, pagers, electronic aids).

(iv) Incorporate into psychological therapy to develop insight and promote adjustment. 
TABle 3: Continued.

\begin{tabular}{lcl}
\hline Consideration/Factor & Evidence & Implications \\
\hline $\begin{array}{l}\text { Stress due to work is a factor } \\
\text { when survivors consider return. }\end{array}$ & {$[55]$} & $\begin{array}{l}\text { (i) Concern about work stress and its possible effects on health } \\
\text { should be considered. }\end{array}$ \\
& (ii) Medical and psychological advice may be helpful.
\end{tabular}

Assets and resources are influential factors in return.

$[55,56,61]$

Psychological disorders are a factor in stroke patients' return to work. (i) Encourage survivors and carers to "audit" their assets and incorporate into their plans.

(ii) Assets may include; family and social networks, healthcare agencies, employers (managers and human resources/personnel, occupational health).

(i) Offer treatment for any psychological conditions such as depression, anxiety or PTSD. the intrinsic rewards of work as an incentive for survivors to take employment, and this is concordant with the results of Scandinavian studies $[62,63]$. Those who valued the intrinsic rewards of work were also the most satisfied [62]. Further individual psychological factors implicated in returning to work were the personal attributes of patience, determination, and sense of humour [56]. Salient work-related concerns expressed by survivors included symptoms that prevented them from working, uncertainty and fear about returning, and the challenges of changing jobs [59].

On the basis of the research reviewed above, some dimensions and specific factors associated with return to work are summarised in Table 2.

\subsection{Helping Stroke Survivors Return to Work: The Evidence} and Its Implications. Work is a major issue for younger stroke survivors and their carers, and rehabilitation should adapt goals to meet their needs and aspirations in this area. There are several employment-related considerations and influential factors that those involved in service development and rehabilitation should consider (Table 3). It is likely that the factors illustrated in Table 3 interact, and case studies and in-depth interviews [64, 67] illustrate how outcomes depended on the interplay of personal factors, and disaffection with alternatives to not working, financial incentives and job characteristics.

In addition to the recommendations in Table 3, Wolfenden and Grace [68] made 13 recommendations for facilitating the return to work of high-functioning workingaged stroke survivors. These were based on a review of the literature and the experiences of one of the authors who was a stroke survivor. These recommendations called for education to raise awareness of the aspirations and needs of stroke survivors, a greater focus on rehabilitation directed towards nonmedical needs such as returning to work, and for rehabilitation to continue for longer after discharge. They also focussed on the workplace and proposed that greater consideration be given to the special needs of the survivor.

Unfortunately, the recommendations in Table 3, and those of Wolfenden and Grace [68], do not map clearly on the roles and responsibilities of multiprofessional stroke rehabilitation teams in many nations (e.g., the UK National
Service Framework for older people [69]) and involve areas of expertise and a degree of interagency working not currently common in rehabilitation services. One promising approach is the development of vocational rehabilitation programmes encompassing the needs of young stroke survivors. Radford and Walker [70] reviewed work after stroke and included studies of vocational rehabilitation for brain-injured people. They concluded that vocational rehabilitation has considerable potential both in terms of individual and cost benefit, but that its application to stroke has been under-researched, and service provision has been patchy, poorly organised and meets only a fraction of the need.

Another development with relevance to the employment of stroke survivors and their carers was the incorporation of peer support into the National Stroke Strategy for England [41]. Peer support for stroke survivors has not been studied, but it has been used successfully with stroke carers [71, 72] and been shown to be beneficial for other health conditions $[73,74]$. As well as enhancing the experience of new stroke survivors and their carers, participation as a peer supporter fulfils the intrinsic functions of work and has potential for enhancing quality of life and re-engaging participants in the benefit and challenges of employment $[75,76]$.

Finally, the use of internet-based resources may help to encourage stroke survivors and inform employers about the employment potential of stroke survivors. These resources may also serve to inform survivors, employers, and carers about practical aspects of return to work. Such information is published on the Different Strokes website in three "Returning to Work After Stroke" documents, one for survivors, one for families and friends, and one for employers [77].

\section{Conclusions and Future Research}

Young stroke survivors have psychological needs which overlap with those of older survivors, but some areas are more prominent in this group. These are mainly associated with being at an earlier life stage, but also stem from the effects of stroke which make them feel "different" and isolated from their young peers and "changed" from their former selves. 
Many of these needs are not met by current stroke services. At an international level there seem to be no plans for separate, dedicated, services for young stroke survivors, therefore it is vital that existing stroke services recognise the special needs of this group and take appropriate action. This will require staff training to develop the capacity to deliver the prerequisite therapies as well as service reconfiguration to enable networking with relevant nonhealth service agencies.

There are no specific psychological interventions designed for young stroke survivors, and while it may not be practicable to develop new age-specific and strokespecific therapies, there is potential to develop guidelines for adapting psychological therapies to meet the particular needs of this group.

With regard to re-engagement with employment, a number of specific recommendations were made on the basis of the literature and are summarised in Table 3. The number and importance of these recommendations, and the singular lack of provision of vocational rehabilitation within existing services, highlights the urgent need for research that will lead to the development of integrated service models and increase access to this vital resource.

The provision of peer support has the potential to meet some of the needs of recovering stroke survivors and of those who have completed their recovery by involvement as volunteers or paid supporters.

\section{References}

[1] V. L. Feigin, C. M. M. Lawes, D. A. Bennett, and C. S. Anderson, "Stroke epidemiology: a review of populationbased studies of incidence, prevalence, and case-fatality in the late 20th century," Lancet Neurology, vol. 2, no. 1, pp. 43-53, 2003.

[2] P. Kersten, J. T. S. Low, A. Ashburn, S. L. George, and D. L. McLellan, "The unmet needs of young people who have had a stroke: results of a national UK survey," Disability and Rehabilitation, vol. 24, no. 16, pp. 860-866, 2002.

[3] Royal College of Physicians, National Clinical Guidelines for Stroke, Royal College of Physicians, London, UK, 3rd edition, 2008.

[4] R. W. Teasell, M. P. McRae, and H. M. Finestone, "Social issues in the rehabilitation of younger stroke patients," Archives of Physical Medicine and Rehabilitation, vol. 81, no. 2, pp. 205209, 2000

[5] C. Gandolfo and M. Conti, "Stroke in young adults: epidemiology," Neurological Sciences, vol. 24, no. 1, pp. S1-S3, 2003.

[6] B. S. Jacobs, B. Boden-Albala, I. F. Lin, and R. L. Sacco, "Stroke in the young in the Northern Manhattan stroke study," Stroke, vol. 33, no. 12, pp. 2789-2793, 2002.

[7] C. L. Bays, "Quality of life of stroke survivors: a research synthesis," The Journal of Neuroscience Nursing, vol. 33, no. 6, pp. 310-316, 2001.

[8] J. S. Kim, S. Choi-Kwon, S. U. Kwon, H. J. Lee, K.-A. Park, and Y. S. Seo, "Factors affecting the quality of life after ischemic stroke: Young versus old patients," The Journal of Clinical Neurology, vol. 1, pp. 59-68, 2005.

[9] H. Naess, U. Waje-Andreassen, L. Thomassen, H. Nyland, and K. M. Myhr, "Health-related quality of life among young adults with ischemic stroke on long-term follow-up," Stroke, vol. 37, no. 5, pp. 1232-1236, 2006.
[10] K. Daniel, C. D. A. Wolfe, M. A. Busch, and C. Mckevitt, "What are the social consequences of stroke for working-aged adults? A systematic review," Stroke, vol. 40, no. 6, pp. e431-e440, 2009.

[11] J. Röding, B. Lindström, J. Malm, and A. Öhman, "Frustrated and invisible - younger stroke patients' experiences of the rehabilitation process," Disability and Rehabilitation, vol. 25, no. 15, pp. 867-874, 2003.

[12] J. Roding, "Stroke in the younger. Self-reported impact on work situation, cognitive function, physical function and life satisfaction. A national survey," Umeå University Medical Dissertations. New Series no. 1241, 2009.

[13] J. Röding, E. L. Glader, J. Malm, and B. Lindström, "Life satisfaction in younger individuals after stroke: different predisposing factors among men and women," Journal of Rehabilitation Medicine, vol. 42, no. 2, pp. 155-161, 2010.

[14] S. D. Stone, "Reactions to invisible disability: the experiences of young women survivors of hemorrhagic stroke," Disability and Rehabilitation, vol. 27, no. 6, pp. 293-304, 2005.

[15] M. Lawrence, "Young adults' experience of stroke: a qualitative review of the literature," British Journal of Nursing, vol. 19, no. 4, pp. 241-248, 2010.

[16] C. C. Keppel and S. F. Crowe, "Changes to body image and selfesteem following stroke in young adults," Neuropsychological Rehabilitation, vol. 10, no. 1, pp. 15-31, 2000.

[17] D. F. Edwards, M. Hahn, C. Baum, and A. W. Dromerick, "The impact of mild stroke on meaningful activity and life satisfaction," Journal of Stroke and Cerebrovascular Diseases, vol. 15, no. 4, pp. 151-157, 2006.

[18] F. Gracey, S. Palmer, B. Rous et al., "'Feeling part of things": personal construction of self after brain injury," Neuropsychological Rehabilitation, vol. 18, no. 5-6, pp. 627650, 2008.

[19] J. B. Cantor, T. A. Ashman, M. E. Schwartz et al., "The role of self-discrepancy theory in understanding post-traumatic brain injury affective disorders: a pilot study," Journal of Head Trauma Rehabilitation, vol. 20, no. 6, pp. 527-543, 2005.

[20] C. Haslam, A. Holme, S. A. Haslam, A. Iyer, J. Jetten, and W. H. Williams, "Maintaining group memberships: social identity continuity predicts well-being after stroke," Neuropsychological Rehabilitation, vol. 18, no. 5-6, pp. 671-691, 2008.

[21] G. Dixon, E. W. Thornton, and C. A. Young, "Perception of self-efficacy and rehabiltation among neurologically disabled adults," Clinical Rehabilitation, vol. 21, no. 3, pp. 230-240, 2007.

[22] M. Cao, M. Ferrari, R. Patella, C. Marra, and M. Rasura, "Neuropsychological findings in young-adult stroke patients," Archives of Clinical Neuropsychology, vol. 22, no. 2, pp. 133$142,2007$.

[23] H. Tajfel and J. Turner, "An integrative theory of intergroup conflict," in The Social Psychology of Intergroup Relations, W. G. Austin and S. Worchel, Eds., pp. 33-47, Brooks-Cole, Monterey, Calif, USA, 1979.

[24] A. Bhalla, R. Grieve, A. G. Rudd, and C. D. A. Wolfe, "Stroke in the young: access to care and outcome; a Western versus Eastern European perspective," Journal of Stroke and Cerebrovascular Diseases, vol. 17, no. 6, pp. 360-365, 2008.

[25] W. Hacke, M. Kaste, J. Bogousslavsky et al., "European stroke initiative recommendations for stroke management-update 2003," Cerebrovascular Diseases, vol. 16, no. 4, pp. 311-337, 2003.

[26] National Stroke Foundation, Clinical Guidelines for Stroke Management 2010 (Draft), National Stroke Foundation, Melbourne, Australia, 2010. 
[27] National Stroke Foundation, Clinical Guidelines for Stroke Rehabilitation and Recovery, National Stroke Foundation, Melbourne, Australia, 2005.

[28] P. Lindsay, M. Bayley, C. Hellings, M. Hill, E. Woodbury, and S. Phillips, "Stroke rehabilitation and community reintegration. Components of inpatient stroke rehabilitation. In: Canadian best practice recommendations for stroke care," Canadian Medical Association Journal, vol. 179, supplement 12, pp. E56E58, 2008.

[29] Stroke Unit Trialists' Collaboration, "Organised inpatient (stroke unit) care for stroke," Cochrane Database of Systematic Reviews, no. 4, article CD000197, 2007.

[30] R. J. O'Connor, E. M. Cassidy, and M. A. Delargy, "Late multidisciplinary rehabilitation in young people after stroke," Disability and Rehabilitation, vol. 27, no. 3, pp. 111-116, 2005.

[31] J. Pringle, C. Hendry, and E. McLafferty, "A review of the early discharge experiences of stroke survivors and their carers," Journal of Clinical Nursing, vol. 17, no. 18, pp. 2384-2397, 2008.

[32] S. Bagg, A. P. Pombo, and W. Hopman, "Effect of age on functional outcomes after stroke rehabilitation," Stroke, vol. 33, no. 1, pp. 179-185, 2002.

[33] L. Kalra, "Does age affect benefits of stroke unit rehabilitation?" Stroke, vol. 25, no. 2, pp. 346-351, 1994.

[34] R. M. Black-Schaffer and C. Winston, "Age and functional outcome after stroke," Topics in Stroke Rehabilitation, vol. 11, no. 2, pp. 23-32, 2004.

[35] Y. Y. K. Kee, W. Brooks, and A. Bhalla, "Do older patients receive adequate stroke care? An experience of a neurovascular clinic," Postgraduate Medical Journal, vol. 85, no. 1001, pp. 115-118, 2009.

[36] J. T. S. Low, P. Kersten, A. Ashburn, S. George, and D. L. McLellan, "A study to evaluate the unmet needs of members belonging to a young stroke groups affiliated with the stroke association," Disability and Rehabilitation, vol. 25, pp. 10521056, 2004.

[37] E. O. Laumann, A. Paik, and R. C. Rosen, "Sexual dysfunction in the United States: prevalence and predictors," Journal of the American Medical Association, vol. 281, no. 6, pp. 537-544, 1999.

[38] M. Bendz, "The first year of rehabilitation after a stroke-from two perspectives," Scandinavian Journal of Caring Sciences, vol. 17, no. 3, pp. 215-222, 2003.

[39] R. Morris, O. Payne, and A. Lambert, "Patient, carer and staff experience of a hospital-based stroke service," International Journal for Quality in Health Care, vol. 19, no. 2, pp. 105-112, 2007.

[40] P. Banks and C. Pearson, Improving Services for Younger Stroke Survivors and Their Families, Chest Heart and Stroke, Edinburgh, Scotland, 2000.

[41] Department of Health, National Stroke Strategy (England), Department of Health, London, UK, 2007.

[42] O. Saka, A. Mcguire, and C. Wolfe, "Cost of stroke in the United Kingdom," Age and Ageing, vol. 38, no. 1, pp. 27-32, 2009.

[43] G. Waddell and A. K. Burton, Is Work Good for your Health and Well-Being? HMSO, London, UK, 2006.

[44] R. M. Black-Schaffer and J. S. Osberg, "Return to work after stroke: development of a predictive model," Archives of Physical Medicine and Rehabilitation, vol. 71, no. 5, pp. 285-290, 1990.

[45] S. Saeki, H. Ogata, T. Okubo, K. Takahashi, and T. Hoshuyama, "Return to work after stroke: a follow-up study," Stroke, vol. 26, no. 3, pp. 399-401, 1995.
[46] S. Saeki and K. Hachisuka, "The association between stroke location and return to work after first stroke," Journal of Stroke and Cerebrovascular Diseases, vol. 13, no. 4, pp. 160-163, 2004.

[47] W. Gabriele and S. Renate, "Work loss following stroke," Disability and Rehabilitation, vol. 31, no. 18, pp. 1487-1493, 2009.

[48] S. Saeki, "Disability management after stroke: its medical aspects for workplace accomodation," Disability and Rehabilitation, vol. 22, no. 13-14, pp. 578-582, 2000.

[49] M. Vestling, B. Tufvesson, and S. Iwarsson, "Indicators for return to work after stroke and the importance of work for subjective well-being and life satisfaction," Journal of Rehabilitation Medicine, vol. 35, no. 3, pp. 127-131, 2003.

[50] K. L. Leung and D. W. K. Man, "Prediction of vocational outcome of people with brain injury after rehabilitation: a discriminant analysis," Work, vol. 25, no. 4, pp. 333-340, 2005.

[51] M. A. Busch, C. Coshall, P. U. Heuschmann, C. McKevitt, and C. D. A. Wolfe, "Sociodemographic differences in return to work after stroke: the South London Stroke Register (SLSR)," Journal of Neurology, Neurosurgery and Psychiatry, vol. 80, no. 8, pp. 888-893, 2009.

[52] N. Glozier, M. L. Hackett, V. Parag, and C. S. Anderson, "The influence of psychiatric morbidity on return to paid work after stroke in younger adults: the auckland regional community stroke (ARCOS) study, 2002 to 2003," Stroke, vol. 39, no. 5, pp. 1526-1532, 2008.

[53] B. Lindström, J. Röding, and G. Sundelin, "Positive attitudes and preserved high level of motor performance are important factors for return to work in younger persons after stroke: a national survey," Journal of Rehabilitation Medicine, vol. 41, no. 9, pp. 714-718, 2009.

[54] S. Saeki and T. Toyonaga, "Determinants of early return to work after first stroke in Japan," Journal of Rehabilitation Medicine, vol. 42, no. 3, pp. 254-258, 2010.

[55] A. Alaszewski, H. Alaszewski, J. Potter, and B. Penhale, "Working after a stroke: survivors' experiences and perceptions of barriers to and facilitators of the return to paid employment," Disability and Rehabilitation, vol. 29, no. 24, pp. 1858-1869, 2007.

[56] L. Koch, N. Egbert, H. Coeling, and D. Ayers, "Returning to work after the onset of illness: experiences of right hemisphere stroke survivors," Rehabilitation Counseling Bulletin, vol. 48, no. 4, pp. 209-218, 2005.

[57] G. Barker, Getting Back to Work after a Stroke, London \& Milton Keynes: Stroke Association/Different Strokes, 2006.

[58] Different Strokes. (undated) Work after stroke project, 2009, http://www.differentstrokes.co.uk/research/was.htm.

[59] G. Gilworth, M. Phil, AD. Cert, K. A. J. Sansam, and R. M. Kent, "Personal experiences of returning to work following stroke: an exploratory study," Work, vol. 34, no. 1, pp. 95-103, 2009.

[60] J. P. Neau, P. Ingrand, C. Mouille-Brachet et al., "Functional recovery and social outcome after cerebral infarction in young adults," Cerebrovascular Diseases, vol. 8, no. 5, pp. 296-302, 1998.

[61] S. Lock, L. Jordan, K. Bryan, and J. Maxim, "Work after stroke: focusing on barriers and enablers," Disability and Society, vol. 20, no. 1, pp. 33-47, 2005.

[62] M. Vestling, E. Ramel, and S. Iwarsson, "Quality of life after stroke: well-being, life satisfaction, and subjective aspects of work," Scandinavian Journal of Occupational Therapy, vol. 12, no. 2, pp. 89-95, 2005. 
[63] J. Medin, J. Barajas, and K. Ekberg, "Stroke patients' experiences of return to work," Disability and Rehabilitation, vol. 28, no. 17, pp. 1051-1060, 2006.

[64] S. Corr and S. Wilmer, "Returning to work after a stroke: an important but neglected area," British Journal of Occupational Therapy, vol. 66, no. 5, pp. 186-192, 2003.

[65] I. Treger, J. Shames, S. Giaquinto, and H. Ring, "Return to work in stroke patients," Disability and Rehabilitation, vol. 29, no. 17, pp. 1397-1403, 2007.

[66] Her Majesty's Government, Disability Discrimination Act (1995-2005), The Stationery Office, London, UK, 2000-2005.

[67] M. L. Chan, "Description of a return-to-work occupational therapy programme for stroke rehabilitation in Singapore," Occupational Therapy International, vol. 15, no. 2, pp. 87-99, 2008.

[68] B. Wolfenden and M. Grace, "Returning to work after stroke: a review," International Journal of Rehabilitation Research, vol. 32, no. 2, pp. 93-97, 2009.

[69] Department of Health, National Service Framework for Older People. Chapter 5: Stroke, Department of Health, London, UK, 2001.

[70] K. A. Radford and M. F. Walker, "Impact of stroke on return to work," Brain Impairment, vol. 9, no. 2, pp. 161-169, 2008.

[71] M. J. Stewart, S. Doble, G. Hart, L. Langille, and K. MacPherson, "Peer visitor support for family caregivers of seniors with stroke," Canadian Journal of Nursing Research, vol. 30, no. 2, pp. 87-117, 1998.

[72] R. J. Hartke and R. B. King, "Telephone group intervention for older stroke caregivers," Topics in Stroke Rehabilitation, vol. 9, no. 4, pp. 65-81, 2003.

[73] M. Doull, A. M. O'Connor, V. Welch, P. Tugwell, and G. A. Wells, "Peer support strategies for improving the health and well-being of individuals with chronic diseases," Cochrane Database of Systematic Reviews, no. 3, article CD005352, 2005.

[74] C. L. Dennis, "Peer support within a health care context: a concept analysis," International Journal of Nursing Studies, vol. 40, no. 3, pp. 321-332, 2003.

[75] K. Pillemer, L. T. Landreneau, and J. J. Suitor, "Volunteers in a peer support project for caregivers: what motivates them?" American Journal of Alzheimer's Disease and Other Dementias, vol. 11, pp. 13-19, 1996.

[76] C. T. Mowbray, D. P. Moxley, S. Thrasher et al., "Consumers as community support providers: issues created by role innovation," Community Mental Health Journal, vol. 32, no. 1, pp. 47-67, 1996.

[77] Different Strokes, 2010, http://www.differentstrokes.co.uk. 


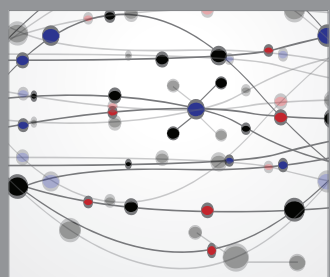

The Scientific World Journal
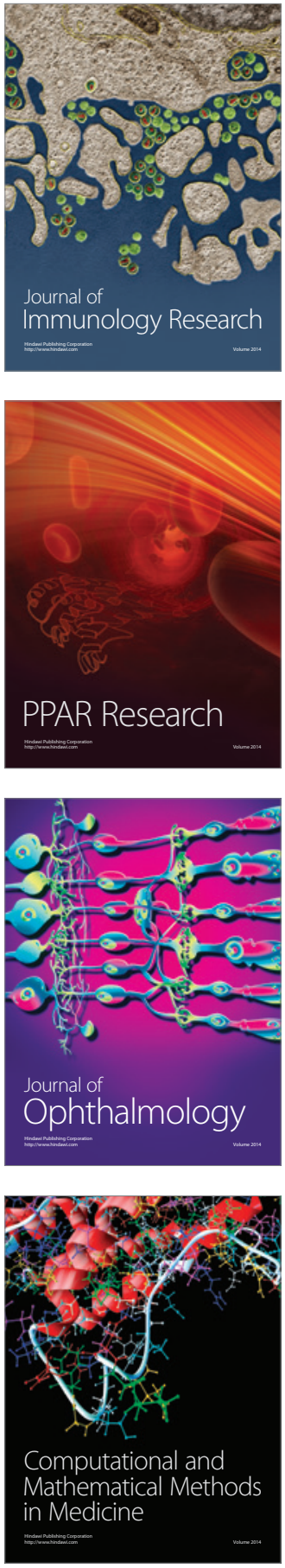

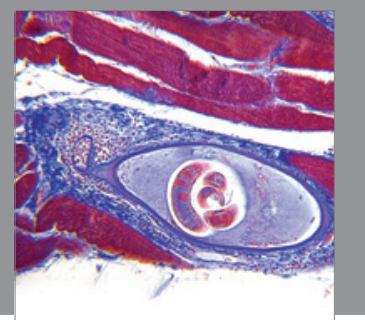

Gastroenterology

Research and Practice
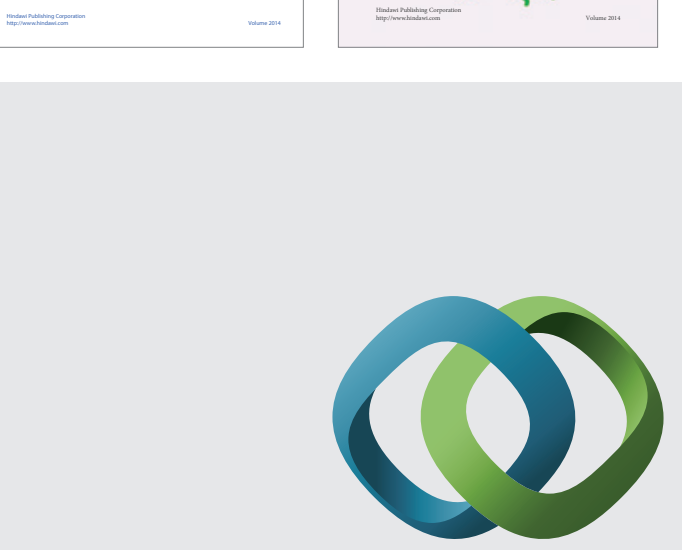

\section{Hindawi}

Submit your manuscripts at

http://www.hindawi.com
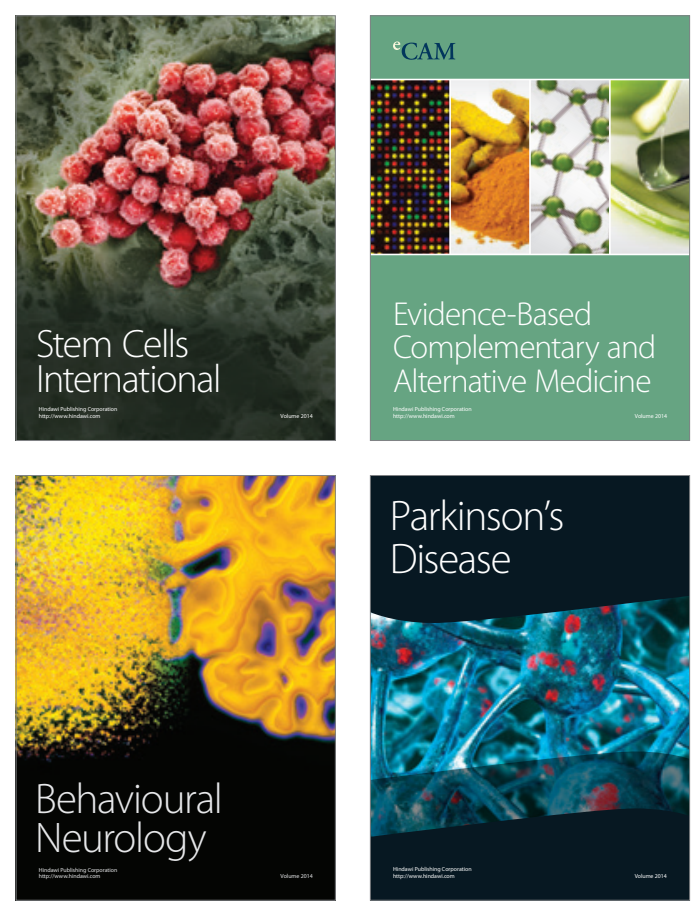

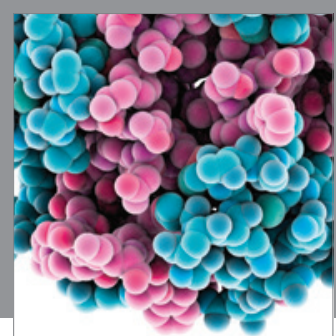

Journal of
Diabetes Research

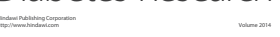

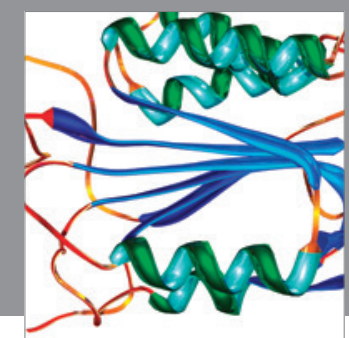

Disease Markers
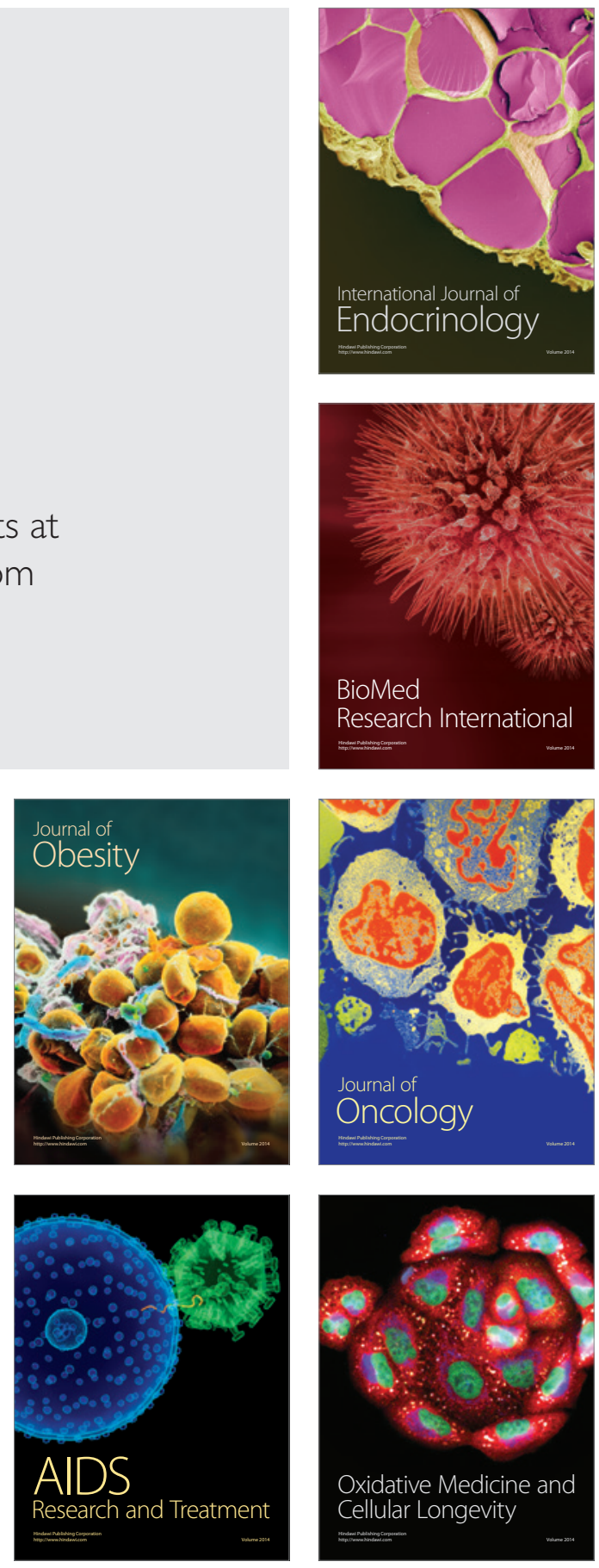